\title{
Intersetorialidade nas ações de promoção de saúde realizadas pelas equipes de saúde bucal de Curitiba (PR)
}

\author{
Intersectoriality in health promotion actions \\ carried out by the oral health team of Curitiba, Paraná State
}

\author{
Andreya Cristina M oretti ${ }^{1}$ \\ Fabrício Farias Teixeira ${ }^{1}$ \\ Fabiane M aria Bortoloso Suss ${ }^{1}$ \\ Juliana A parecida de Campos Lawder ${ }^{1}$ \\ LucianeSilveira M iranda de Lima ${ }^{1}$ \\ Roberto Eduardo Bueno ${ }^{1}$ \\ Samuel Jorge M oysés ${ }^{1}$ \\ Simone Tetu Moysés ${ }^{1}$
}

Abstract This study sought to explore the intersectoral actions developed by the oral health teams of Curitiba, Paraná State, and to analyze the local managers' perception about intersectoral approach. A cross-sectional study with quantitative and qualitative methodology was used, with data collection by a self-response questionnaire and focal group technique. The results showed that most health promotion actions carried out by the teams are interdisciplinary and when other sectors are involved it is in turning physical spaces available, without jointed and integrated perspectives. The managers' perception reinforces in the concept the teams' practices. It was observed that the Family $\mathrm{H}$ ealth Strategy facilitate intersectoral actions and the intersectorality is a challenging way of work, but possible to become reality.

Key words Intersectorial action, Health promotion, Oral health
Resumo 0 objetivo deste estudo foi explorar as ações intersetoriais desenvolvidas pelas equi pes de saúde bucal na rede M unicipal de Saúde de Curitiba (PR) e analisar a percepção dos gestores locais ligados a estas equipes sobre a intersetorialidade. U tilizou-se um modelo de estudo transversal demetodologia quantitativa equalitativa, com coleta de dados por meio de um questionário autoaplicável e a técnica do grupo focal. O s resultados mostraram que as maiorias das ações de promoção de saúde realizadas pelas equipes são interdisciplinares e quando há envolvimento de outros setores é na disponibilização de espaços físicos, sem uma perspectiva de ação conjunta e integrada. A percepção dos gestores reitera no conceito as práticas das equipes. O bservou-se que a Estratégia da Saúde da Família é facilitadora de ações intersetoriais eque, a pesar das dificuldades, a intersetorialidade é uma forma de trabalho de safiadora, mas possível de tornar-se realidade. Palavras-chave Intersetorialidade, Promoção de saúde, Saúde bucal

\footnotetext{
${ }^{1}$ Pontifícia Universidade Católica do Paraná. Rua Imaculada Conceição 1155, Prado Velho. 80215-901 Curitiba PR.

andreyamoretti@hotmail.com
} 
Introdução

Promover saúde é uma estratégia complexa que implica a compreensão da relação do homem ou das populações com sua história, seus padrões de desenvolvimento, suas relações com o mundo, com seu ambiente sociocultural, com suas necessidades, direitos e condições de vida. Portanto, promover saúde é atuar sobre estes determinantes que condicionam a realização da saúde ${ }^{1,2}$.

Sigerist ${ }^{3}$, na década de quarenta, afirmava que a saúde se promove proporcionando condições devida decentes, boas condições detrabalho, educação, cultura física e formas de lazer e descanso.

A construção do conceito ampliado eda aplicação do que se entende por promoção de saúde, atualmente, reconhece quea promoção da saúde e do desenvolvimento social é um dever e responsabilidade central dos governos, compartiIhada por todos os setores da sociedade, colocando sua concretização como prioridade fundamental das políticas e programas de todas as esferas dos governos. Assim, as soluções para a promoção da saúde estão além de um sistema de saúde nos moldes tradicionais, voltado apenas para a assistência à doença. As iniciativas devem partir de todos os setores através de parcerias e redes de colaboração unidas em estabelecer metas eações conjuntas que possam contribuir para a criação de ambientes mais favoráveis e fomentadores de saúde $e^{4-8}$.

A nova Política Nacional de Promoção de Saúde ${ }^{9}$ compreende a intersetorialidade como uma articulação entreos distintos setores no pensar a questão complexa da saúde, assumir a corresponsabilização pela garantia da saúde como direito humano e de cidadania e mobilizar-sena formulação de intervenções que a propiciem.

0 processo de construção de ações intersetoriais voltadas para a promoção da saúde implica a troca e a construção coletiva de saberes, linguagens e práticas entre os diversos setores envolvidosna tentativa de equacionar questões sani-tárias, produzindo soluções inovadoras para a melhoria da qualidade de vida deforma democrática eresoIutiva. Desta forma, a intersetorialidade implica a existência de algum grau de abertura em cada setor envolvido para dialogar, estabelecendo vínculos de corresponsabilidadee cogestão pela melhoria da qualidade de vida da população ${ }^{10}$.

A ação intersetorial éum processo de aprendizagem e determinação dos sujeitos, que deve resultar em uma gestão integrada, capaz de responder com eficácia a solução de problemas da população de um determinado território ${ }^{11}$.
0 desenvolvimento de ações com base territorial, buscando a integração com instituiç̧̃̃es e organizações sociais para o desenvolvimento de parcerias que garantam a construção da cidadania, é partedos princípios gerais da atual Política Nacional de Atenção Básica no Brasil ${ }^{12}$. Esta política aponta como atribuições de todos os profissionais das equipes desaúde, em especial aqueles atuando na Estratégia de Saúde da Família, desenvolver ações intersetoriais, buscando parcerias e recursos na comunidade que possam potencializar estas ações, além de favorecer a integração de projetos sociais e setores afins voltados para a promoção de saúde.

o protagonismo e compromisso do setor saúde na articulação intersetorial é, portanto, cada vez mais importante, apontando, na várias esferas de decisão, para a pertinência de considerar aspectos ligados ao processo saúde-adoecimento como parte de políticas específicas detodos os setores envolvidos com a melhoria da qualidade de vida da população?

A ação intersetorial é também uma estratégia importante para a reorganização da atenção em saúde bucal em todos os níveis de aten ção, tendo o conceito do cuidado como eixo dereorientação do modelo. As diretrizes da atual Política Nacional de SaúdeBucal ${ }^{13}$ indicam a necessidadede incorporação de ações programáticas abrangentes e o desenvolvimento de ações intersetoriais para reforçar a concepção de saúde não centrada somente na assistência aos doentes mas, sobretudo, na promoção da boa qualidade de vida e intervenção nos fatores que a colocam em risco.

0 objetivo desteestudo foi identificar a intersetorialidade nas ações de promoção de saúde desenvolvidas pelas equipes de saúde bucal na rede municipal desaúde de Curitiba (PR), explorando as ações intersetoriais desenvolvidas em Unidades de Saúde Básicas e com Estratégia de Saúde da Família. Foi propósito também deste estudo analisar a percepção sobre intersetorialidade na atenção em saúde dos gestores locais ligados a estas equipes.

\section{Materiais e método}

O presente trabalho utilizou-se de um modelo de estudo transversal edemetodologia quantitativa e qualitativa para a análise da intersetorialidade nas ações de promoção de saúde desenvolvidas pelas equipes de saúde bucal da rede de saúde do município deCuritiba, bem como da percepção dos gestores locais das equipes sobre este tipo de ação. 
A primeira fase do estudo compreendeu a coleta de informações com o objetivo de estabelecer um diagnóstico situacional da intersetorialidade nas ações de promoção de saúde desenvolvidas pelas equipes de saúde bucal. Os dados foram coletados de todas as Unidades de Saúde com equipe de saúde bucal da rede municipal de saúde de Curitiba, distribuídas em novedistritos sanitários. Foram excluídas as Unidades de Saúde com menos de um ano de atuação, período consi derado insuficiente para avaliação de ações intersetoriais, perfazendo um total de 94 unidades. 0 instrumento utilizado foi um questionário autoaplicável, respondido por um membro da equipe de saúde bucal local. 0 questionário foi acompanhado de um texto explicativo do objeto de pesquisa e do termo de consentimento livreeesclarecido.

A análise dos dados do questionário foi realizada de modo a explorar as respostas sobre a realização de ações intersetoriais de promoção de saúde desenvolvidas pelas equipes de saúde bucal, considerando o tipo de estratégia de atenção na unidade (Unidade Básica de Saúdeou Estraté gia de Saúde da Família). A caracterização das ações descritas como ações intersetoriais foi baseada nos critérios propostos por Campos e Teixeira ${ }^{14}$, em que ações intersetoriais referem-se a iniciativas que contam com a interação de dois ou mais órgãos pertencentesa setores sociais ou econômicos diferentes, no interior do Estado, ou com entidades da sociedade civil, que executam ações tipificáveis como características de determinado setor de atuação pública. Tal interação pode se dar num contínuo que vai da ação articulada e a coordenação das respectivas estruturas, atéo que se denomina gestão transversal, passando por gradações entre esses dois pólos. A mera cessão de ben sou estruturas como espaço físico, ou o simples financiamento, ou qualquer outra participação de órgãos públicos ou ON Gs que não seja relacionada ao planejamento, coordenação, avaliação ou execução direta das atividades do projeto não pode, portanto, ser conside rada como atividade intersetorial.

A segunda fase do estudo pretendeu avaliar a percepção sobre intersetorialidade dos gestores locais da rede municipal de saúde de Curitiba. Para a coleta de dados, foi utilizada a técnica do grupo focal. A composição do grupo focal é formada por participantes com características comuns ${ }^{15}$; neste caso, a experiência em relação ao tema. Optou-se por uma amostra intencional, composta por uma gestor local de Unidades de Saúde em cada um dos nove distritos sanitários, indicados pelas gerências distritais.
Um moderador e dois observadores conduziram a discussão do grupo com base em um roteiro de temas preestabelecidos, a qual foi gravada e transcrita para posterior análise. Os participantes do grupo expressaram sua vontade de participar através da assinatura do termo de consentimento livre e esclarecido, constante no projeto e aprovado pelo Comitê de Ética em Pesquisa da Secretaria M unicipal da Saúde de Curitiba.

A análise do material desta etapa foi feita através de uma avaliação qualitativa, que consistiu na organização do material selecionado, na divisão das partes com identificação de tendências e padrões semelhantes, apresentação e descrição dos dados, análise dos dados através do cruzamento deopiniões divergentes edo próprio ponto de vista dos pesquisadores e autores utilizado como referência ${ }^{16}$.

\section{Resultados ediscussão}

0 universo do estudo foi composto por 94 Unidades de Saúde. Dos questionários encaminhados às equipes de saúde bucal, obteve-se devolução de 67 questionários, correspondendo a uma taxa de resposta de 71,27\%. Das 67 unidades que devolveram o questionário preenchido, 37 (55,2\%) eram equipes atuando em Unidades Básicas e trinta (44,8\%) atuando em Estratégia de Saúde da Família.

Do total de respondentes, 65 (97\%) consideraram que realizam alguma ação intersetorial de promoção de saúde em articulação com outros setores. Duas equipes (3\%) responderam quenão realizavam nenhuma ação intersetorial.

Entretanto, a análise de conteúdo dos questionários das 65 equipes que afirmaram real izar ações intersetoriais evidenciou que apenas quinze $(23,1 \%)$ das equipes relataram ações com características que justificaram a qualificação da ação como intersetorial e cinquenta $(76,9 \%)$ equipes relatavam ações setoriais desenvolvidas em outros espaços que não os ligados ao setor saúde.

As equipes de saúde bucal citaram diversas ações, identificadas pelas mesmas como promotoras de saúde e intersetoriais. A maior parte se referia a ações de educação em saúde bucal, palestras educativas, levantamentos epidemiológicos, escovação supervisionada, aplicação tópica com flúor e bochechos fluoretados, real izadas em outros espaços, geralmente em escolas, centros de educação infantil eoutras instituições de ensino. Outros locais foram mencionados para a realização destas atividades, como empresas, enti- 
dades comunitárias, igrejas, inclusive a própria unidade de saúde na interação com os programas desenvolvidos por outros membros da equipe multiprofissional de uma unidade de saúde (hipertensos, gestantes, entre outros).

Quando se identificaram os parceiros citados pelas equipes, o setor educação apareceu em $94,1 \%$ das respostas. Whestpal e $M$ endes ${ }^{8}$ relatam que os setores da saúde, educação e ação social parecem ser os parceiros mais comuns quando seavaliam experiênciasintersetoriais, mas que muitas dessas iniciativas são informais e não envolvem um trabalho prévio de planejamento, sendo ações definidas por apenas um setor.

Práticas educativas e de prevenção de doenças bucais em escolas têm sido tradicionalmente desenvolvidas por equipes de saúde bucal. Uma das justificativas para estas ações é que o espaço da escola pode facilitar o acesso a um maior número de crianças. Entretanto, na maioria das vezes, estas ações são desenvolvidas deforma isolada, provocando efeitos positivos temporários, mas pouco impactantes em melhorias das condições de saúde bucal da população. Ações de promoção de saúde ampliadas, com o envolvimento de toda a comunidade escolar no processo de fazer deste um espaço favorável à saúde, têm sido considerados mais efetivos ${ }^{17}$.

Outras ações pontuais foram citadas pelas equipes como "atividade de relaxamento corporal", "ação para redução da mortalidade materno-infantil", "educação para o aproveitamento dos alimentos", "arborização da beira do rio com a população", "reciclagem de lixo (meio ambiente): educação nos depósitos", "participação no conseIho local de saúde", "atividades com a pastoral da criança". A prática da intersetorialidadeéum processo difícil e complexo; foi possível perceber o surgimento de ações potencialmente intersetoriais, mas a maioria delas ainda são centradas na interdisciplinaridade, em uma relação mais próxima dos atores sociais e entre os diversos profissionais dos diferentes níveis de atenção em saúde, mas sem um envolvimento de planejamento que permita o reconhecimento dos diversos saberese da interlocução de outros setores envolvidos, gerando ações fragmentadas e de pouco impacto.

As ações qualificadas neste estudo como intersetoriais referiam-se a ações com evidências devínculos de corresponsabilidade entreos setores envolvidos. N esta perspectiva, foram citadas ações de incentivo à alimentação saudável, atividades visando à educação do cidadão para viver em sociedade e promover sua autonomia, prevenção ao uso e abuso de substâncias como ál- cool ou outras drogas, reciclagem de lixo, cuidados com o meio ambiente e escolas promotoras de saúde.

A concepção ampliada de saúde, embasada em determinantes socioambientais e em outras áreas do conhecimento, além dos fatores meramente biológicos, é reconhecidamente a melhor forma de se estabelecer estratégias eficazes de promoção de saúde e esta visão ampliada foi manifestada pelas equipes cujas ações foram qualificadas como promotoras de ações intersetoriais.

0 reconhecimento da contribuição destas ações para a saúde dos grupos assistidos foi identificado pelos respondentes como potencializador das ações educativas/preventivas dos diferentes atores envolvidos, estimulando o resgate da cidadania ea construção da autonomia, além da mobilização da comunidade para a responsabilização pelo autocuidado, pelo meio ambiente, através do fortalecimento do vínculo com outros setores.

Além disso, foi reconhecido quea construção de ações intersetoriais permite pensar as necessidades da comunidade de forma mais ampla e de agir nos problemas de forma menos pontual, considerando toda sua complexidade.

Os relatos destas equipes estão de acordo com a visão ampliada de promoção de saúde, na intenção de promover a autonomia das comunidades, fortalecendo a participação comunitária e agindo intersetorialmente na resolução de problemas que atinjam suas comunidades de atuaçãa $78,18,19$.

Dificuldades na realização de ações intersetoriais também foram apontadas pelos respondentes. Dentreelas, destacam-sea dificuldade deconciliar os tempos institucionais dos vários setores, o comprometimento e envolvimento setorial, a sustentabilidade das ações, além da inexistência de protocolos que norteiem o desenvolvimento de ações intersetoriais.

Uma política nacional de promoção de saúde deve estar comprometida com serviços e ações de saúde que coloquem usuários e profissionais de saúde como protagonistas na organização do processo produtivo em saúde, entendendo que ali se produz saúde ${ }^{10}$.

Esse conhecimento deve ser estimulado na formação curricular e na educação continuada no âmbito do SUS, além da discussão de indicadores ou práticas de promoção de saúde protocolares que reorientem os processos de trabal ho das equipes. No caso específico de equipes de saúde bucal, o estímulo à implantação de novas equipes descentralizadas e territorializadas é um caminho interessantepara incentivar o envolvimen- 
to em ações intersetoriais, mas não eficaz se a prática profissional se mantiver centrada no modelo curativo.

0 modelo de atenção parece influenciar 0 desenvolvimento de ações intersetoriais pelas equipes de saúde bucal. Do total de 35 unidades básicas participantes, apenas três ( $8,6 \%$ ) tiveram suas ações qualificadas como intersetoriais e 32 $(91,4 \%)$, como ações setoriais desenvolvidas em outros espaços. Das trinta unidades de saúde com ESF que responderam o questionário, doze $(40 \%)$ foram consideradas ações intersetoriais e dezoito (60\%), qualificadas como ações setoriais desenvolvidas em outros espaços.

A Política Nacional de Atenção Básica ${ }^{12}$ tem como um dos seus princípios gerais, quando trata das especificidades da Estratégia da Saúde da Família, a busca da integração com instituições e organizações sociais em suas áreas de abrangência para o desenvolvimento de parcerias. Os re sultados verificados neste estudo indicam que a Estratégia da Saúde da Família éum recurso facilitador deações intersetoriais pelas equipes desaúde bucal quando utilizado dentro de seus princípios norteadores. A descentralização proposta no SUS facilita, mas impõe uma necessidade de gestores locais informados econscientes de uma gestão baseada no conhecimento territorial e na integração com a comunidadee reconhecimento de seus problemas, que busque soluções e iniciativas com os recursos e parcerias dentro de suas áreas deabrangência. Portanto, éreconhecido quea boa gestão local éum recurso importanteenecessário para o desenvolvimento de ações intersetoriais.

\section{A percepção dos gestores}

A presentamos aqui o relato e a discussão sobre os depoimentos feitos pel os participantes do grupo focal. A análise do discurso dos sujeitos envolvidos explorou as ações intersetoriais através da percepção do conceito de intersetorialidade, da prática das ações intersetoriais e da participação da odontologia nas ações intersetoriais.

Como já abordado na discussão teórica, 0 conceito de intersetorialidadeenfoca intervenções em fatores socioambientais que afetem a saúde das comunidades de uma maneira coletiva e envolve estabelecimento de parcerias com setores fora da área da saúde. O bservou-se, com os relatos dos entrevistados, que na maioria das vezes não havia clareza sobre este contexto, confundindo a interdisciplinaridade e a mera concessão de espaço físico e bens materiais para a realização das ações, sem denotar corresponsabilidade:
Q uando o dentista, um ACD ou um THD é convidado para fazer uma palestra sobresaúde bucal em um grupo de gestantes, então isso é um tipo de intersetorialidade que existe.

Assim, em algum momento, foi bem bacana que a própria odontologia começou planejar e daí foi lá e chamou alguém da enfermagem para ajudar no planejamento, eles montaram um modelo para se trabalhar com os adol escentes nas escolas.

A equipe da odonto que trabalha na Rede de Proteção [a crianças e adolescentes em situação de risco à violência] faz visitas, recebe as comunicações e reuniões. Faz um trabal ho que na verdade seria da enfermagem, maselasqueacabam fazendo e se dão muito bem. Se é certo ou errado, eu não sei, estou colocando a realidade local.

A interdisciplinaridade nas ações esteve presente no relato de vários discursos dos gestores. Em alguns casos, o conceito se confunde com a da intersetorialidade nas fal as, mas é interessante perceber que este pode ser o primeiro passo para ações intersetoriais. Uma equipequeconseguetrocar experiências e saberes na resolução de problemas tem uma grande chance de ampliar sua atuação intersetorial no território. A interdisciplinaridade éfavorecida na Estratégia da Saúde da Família, em que o processo de trabalho promove 0 encontro e ação conjunta das equipes.

Exemplos de ações intersetoriais desenvolvidas por membros das equipes de saúde bucal foram apontados pelos gestores: A odontologia inclusive está inserida na rede de proteção, onde duas pessoas, da odontologia, trabalham, visitam junto com o consel ho tutelar, trabalham com 0 bolsa família.

Temos lá um outro projeto que éa refei ção solidária. A gente tem uma parceria com os voluntários da comunidade, com a igreja, com uma empresa que fornece as refeições prontas e balanceadas por uma nutricionista, com uma outra empresa que busca a sopa, uma parceria com a secretaria de abastecimento, com empresa que fornece as vasil has, são várias pessoas envolvidas nesse projeto. 0 objetivo não é só entregar a sopa, se fosse esse a gente colocaria ali e eles mesmos se serviriam. 0 objetivo começou pela sopa para quea gente tivesse uma integração com essas famílias. Com isso também conseguimos cobrir e superar nossa metas de vacina que tínhamos dificuldade de atingir por causa dessa comunidade.

M uitos dentistas participam do Alfabetizando com Saúde, onde se conseguiu incluir a saúde bucal.

Alguns aspectos puderam ser captados nos discursos dos gestores para justificar o envolvimento de equipes de saúde bucal em ações inter- 
setoriais, facilitando sua saída para fora do espaço da clínica e assumindo a linha de frente em ações no território através de contatos intersetoriais, principalmente no espaço da escola. Entre estes fatores, estão a disponi bilização para o trabalho externo ao ambulatório ea inserção histórica na escola:

Existe assim uma pressão pelo recurso médico, a gente tinha mais dificuldade detirar o médico da unidade do que o dentista, THD ou ACD, então a gente acabava utilizando esse recurso. $\mathrm{E}$ aí acho que foi, no meu entender, na minha experiência, 0 que facilitou decerta forma para quea odontologia se vinculasse nos espaços extramuros fora da clínica odontológica, o que permitiu queela sedimentassee divulgasse seu trabal ho junto às comunidades.

A odontologia na verdade é uma ligação da unidade desaúde com as escolas. Entra a odontologia, mas depois começa outras ações das unidades desaúde. Ela quetem todos os contatos nas escolas, tem as portas abertas mesmo, para estar parceiro na escola.

Os relatos dos gestores confirmam a aposta das diretrizes da nova Política de Saúde Bucal ${ }^{13}$, que tem a Estratégia da Saúde da Família como caráter substitutivo ao modelo de atenção básica tradicional, sendo um recurso que oportuniza a integração do território econsequentemente oferece possibilidades maiores da realização de ações intersetoriais: Têm diferenças entre unidade básica ePSF. Então, assim, eu concordo que na unidadePSF a coisa conseguechegar, né? E numa unidade básica parece que a tendência é ficar mais nas escolas mesmo.

0 perfil profissional também foi apontado como fator importante para o desenvolvimento de ações desta natureza, o que reforça a necessidade de uma formação acadêmica voltada para o desenvolvimento de profissionais que possam influenciar as condições de vida e saúde das pessoas: Varia muito qual é a unidade, o dentista ou quando vocêtem um ACD ou TH D que é extraordinário, super. Ele consegue sobressair. Depende muito da pessoa, da visão que ela tem enão éuma coisa padrão.

A literatura atual sobre promoção de saúdeé contundente ao mostrar que ações que não levem em conta o conceito ampliado de saúde e os determinantes socioambientais estão fadadas a práticas repetitivas e de impacto limitado.

A nova política de saúde bucal brasileira sugere a reorientação do processo de trabalho das equipes de saúde bucal para assumir uma postura que se responsabilize pelos problemas da população e sugere para isso o rompimento de ve
Ihas práticas. 0 investimento na atenção básica, assumida pela atual gestão, parece o melhor caminho, já que a territorialização permite um conhecimento das diferentes e desiguais comunidades deste país. M as para que esta proposta não se torne apenas e também uma repetição de velhas práticas, agora territorializadas, é importante a responsabilidade dos gestores, em todos os níveis, com essa proposta de governar. 0 investimento deve começar pela formação de novos profissionais voltados para a responsabilização da saúde da população, além do incentivo à educação continuada, prevista em lei, no interior do SUS. Processos avaliativos são também uma clara necessidade para que o desenvolvimento de ações intersetoriais se estabel eça como rotina, e a construção de indicadores e protocolos que levem em conta a promoção de saúde como diretriz, seja em atividades coletivas ou na clínica ampliada, devem fazer parte de nova maneira de pensar.

Assim entendemos, como Westphal e Mendes $^{8}$, queembora com dificuldade, a intersetorialidade é uma forma de gestão possível e muito eficiente em termos da promoção do desenvolvimento econômico e social.

\section{Consideraçõesfinais}

Percebe-se neste estudo quea realização de práticas intersetoriais é ainda um desafio a ser conquistado, mas queéuma prática possível, principalmente quando amparada e estimulada por uma boa gestão local.

O conceito e a prática da intersetorialidade precisam ser inseridos na rotina de gestores e profissionais de saúde para que ações de promoção de saúde não se tornem a repetição demodelos conhecidos e reconhecidamente pouco impactantes na melhoria de condições de saúde bucal da população. A responsabilidade sobre essa nova forma de olhar e cuidar não deve ser atribuída exclusivamente a esses atores, mas em políticas voltadas a facilitar a articulação dos setores governamentais enão governamentais, controle e responsabilização social, estimulando a educação continuada de profissionais de saúde no protagonismo dessas ações.

0 impacto em saúdee, em especial, em saúde bucal, das ações intersetoriais desenvolvidas pelas equipes não foi o foco deste estudo, mas a avaliação qualitativa mostrou um rompimento, ainda que tímido, de ações estritamente centradas na atenção às doenças bucais. As respostas e 
discursos das equipes e gestores locais demonstraram que é possível, quando há conhecimento e boa vontade, mudar e melhorar as realidades locais.

\section{Colaboradores}

AC M oretti FF Teixeira participou da revisão bibliográfica, pesquisa, metodologia, grupo focal análise dos questionários, construção da monografia e redação final. FM B Suss, LSM Lima eRE Bueno participaram darevisão bibliográfica, pesquisa, metodologia, grupo focal, análise dos questionários e construção da monografia. J AC Lawder participou da revisão bibliográfica, pesquisa, metodologia, análise dos questionários, construção da monografia, redação final e formatação do trabalho. SJ M oysés eST M oysés orientaram o trabalho e a redação final.

\section{Referências}

1. Focesi E. Educação em saúde: campos de atuação na área. Rev. Bras. Saúde Escolar 1990; I:19-21.

2. Moysés ST, Watt R. Promoção de Saúde Bucal definições. In: Buischi YP. Promoção da Saúde Bucal na Clínica Odontológica. São Paulo: Artes M édicas; 2000. p. 1-22.

3. Sigerist H. In: Czeresnia D, Freitas CM, organizadores. Promoção de saúde: reflexões, conceitos, tendências. Rio de Janeiro: Fiocruz; 2003.

4. Andrade LOM, Barreto ICHC. Promoção da saúde e cidades/ municípios saudáveis: Propostas de articulação entre saúde e ambiente. In: M inayo MCS, M iranda AC. Saúde e ambiente sustentáveis: estreitando nós. Rio de Janeiro: Abrasco-Fiocruz; 2001. p. 148-205.

5. Brasil. Ministério da Saúde. As cartas da promoção de saúde. Brasília: M inistério da Saúde; 2002.

6. Buss PM. U ma introdução ao conceito de promoção de saúde. In: Czeresnia D. Promoção da saúde: conceito, reflexões, tendências. Rio de Janeiro: Fiocruz; 2003. p.15-38.

7. Moysés SJ, Moysés ST, Krempel MC. Avaliando o processo de construção de políticas públicas de promoção de saúde: a experiência de Curitiba. Cien Saude Colet 2004; 9(3):627-641.

8. Westphal MF, Mendes R. Cidade saúdavel: uma experiencia de interdisciplinaridade e intersetorialidade. Rev. Adm. Pública 2000; 34(6):47-61.

9. Brasil. M inistério da Saúde. Política Nacional de Promoção da Saúde. Brasília: M inistério da Saúde; 2006.

10. Campos GW, Barros RB, Castro AM. Avaliação de política nacional de promoção da saúde. Cien Saude Colet 2004; 9(3):745-749.

11. Junqueira LP. A gestão intersetorial das políticas sociais e o terceiro setor. Saúde e Sociedade 2004; 13(1):25-36. 
12. Brasil. M inistério da Saúde. Política N acional deAtenção Básica. Braślila: M inistério da Saúde; 2006.

13. Brasil. Ministério da Saúde. As diretrizes da política nacional de saúde bucal. Brasília: Ministério da Saúde; 2004.

14. Campos FC, Teixeira PF. Promoção de saúde na atenção básica no Brasil. [site da Internet]. 2005 [acessado 2007 jan 12];[350 páginas]. Disponível em: http:// dtr2004.saude.gov.br/dab/docs/geral/promocao saude_ab.pdf

15. Flick U. U ma introdução à pesquisa qualitativa. $2^{\underline{a}}$ ed. Porto Alegre: Bookman; 2004.

16. Nogueira-M artins M CF, Bógus CM. Considerações sobre a metodologia qualitativa como recurso para o estudo das ações de humanização em saúde. Saúde e Sociedade 2004; 13(3):44-57.

17. Moysés ST, Moysés SJ, Watt RG, Sheiham A. Associations between health promoting schools' policies and indicators of oral health in Brazil. Health Prom Int 2003; 18(3):209-218.

18. Chaves M. Complexidade e transdisciplinaridade: uma abordagem multidimensional do setor saúde Rev. bras. educ. med.1998; 22(1):7-18.

19. Wimmer GF, Figueiredo GO. Ação coletiva para qualidade de vida: autonomia, transdisciplinaridade e intersetorialidade. Cien Saude Colet 2006; 11(1):145-154

Artigo apresentado em 26/09/2007

Aprovado em 06/04/2008

Versão final apresentada em 06/08/2008 